\title{
SOUTH AFRICA: \\ TIME RUNNING \\ OUT
}

The Report of the Study Commission on U.S. Policy Toward Southern Africa 
University of California Press

Berkeley and Los Angeles, California

University of California Press, Ltd.

London, England

Copyright (c) 1981 by Foreign Policy Study Foundation, Inc.

All rights reserved.

\section{Library of Congress Cataloging in Publication Data}

Study Commission on U.S. Policy Toward Southern Africa South Africa: Time running out

1. United States-Foreign relations-South Africa.

2. South Africa-Foreign relations-Unites States.

I. Title

E182.8.S6S78 $1981 \quad 327.73068 \quad 81-2742$

cloth ISBN 0-520-04594-1

AACR2

paper ISBN 0-520-04547-5

Printed in the United States of America

Book design by Samuel N. Antupit

Maps by General Cartography, Inc. 